\title{
The Formation of Spore-Like Akinetes: A Survival Strategy of Filamentous Cyanobacteria
}

\author{
Ritu Garg Iris Maldener \\ Institute of Microbiology and Infection Medicine, Organismic Interactions, University of Tübingen, Tübingen, Germany
}

\section{Keywords}

Cyanobacteria - Anabaena - Akinete - Heterocyst .

Germination · Envelope $\cdot$ Stress resistance

\section{Abstract}

Some cyanobacteria of the order Nostocales can form akinetes, spore-like dormant cells resistant to various unfavorable environmental fluctuations. Akinetes are larger than vegetative cells and contain large quantities of reserve products, mainly glycogen and the nitrogen storage polypeptide polymer cyanophycin. Akinetes are enveloped in a thick protective coat containing a multilayered structure and are able to germinate into new vegetative cells under suitable growth conditions. Here, we summarize the significant morphological and physiological changes that occur during akinete differentiation and germination and present our investigation of the physiological function of the storage polymer cyanophycin in these cellular processes. We show that the cyanophycin production is not required for formation and germination of the akinetes in the filamentous cyanobacterium Anabaena variabilis ATCC 29413.

(c) 2021 The Author(s)

Published by S. Karger AG, Basel

\section{Introduction}

\section{Cell Differentiation in Filamentous Cyanobacteria}

The ability to differentiate specialized cells during the adaptation to environmental changes is a hallmark of filamentous cyanobacteria, which represent original multicellular organisms. Well-studied representatives of these filamentous cyanobacteria belong to the order Nostocales, including Anabaena variabilis ATCC 29413 and Nostoc punctiforme PCC 73102. Under favorable conditions, aquatic forms can grow in filaments of hundreds of cells, which are directly connected by cell-cell junctions [Flores et al., 2016, 2019; Kieninger et al., 2019]. These allow communication between cells all along the filament and, as a consequence, a rapid response to stress signals with a complete division of labor between different cell types [Weiss et al., 2019]. For instance, upon nitrogen starvation, about $10 \%$ of semi-randomly spaced cells can differentiate into nitrogen-fixing heterocysts, which support the filaments with nitrogen, presumably through the septal junctions. Another example of specialized cell type is represented by motile short filaments - the hormogonia - which enable dispersal of the cyanobacteria by float- karger@karger.com www.karger.com/mip

Karger $\stackrel{\text { ' }}{=}$
(C) 2021 The Author(s)

Published by S. Karger AG, Basel

This is an Open Access article licensed under the Creative Common Attribution-NonCommercial-4.0 International License (CC BY-NC) (http://www.karger.com/Services/OpenAccessLicense), applicable to the online version of the article only. Usage and distribution for commercial purposes requires written permission.
Correspondence to:

Iris Maldener, iris.maldener@uni-tuebingen.de 
Fig. 1. Schematic representation of the life cycle of cyanobacteria of the order Nostocales. Under favorable growth conditions, vegetative cells can successively grow and divide forming long filaments. In absence of combined nitrogen sources, some vegetative cells differentiate into heterocysts, which can fix atmospheric nitrogen. Akinetes are formed under unfavorable conditions, such as nutrient starvation, low light, and low temperature. Akinetes are resting cells, which can survive under harsh environmental conditions. Finally, if the conditions are sufficiently favorable, the wall of akinetes ruptures, allowing germination and re-growth of the filaments.

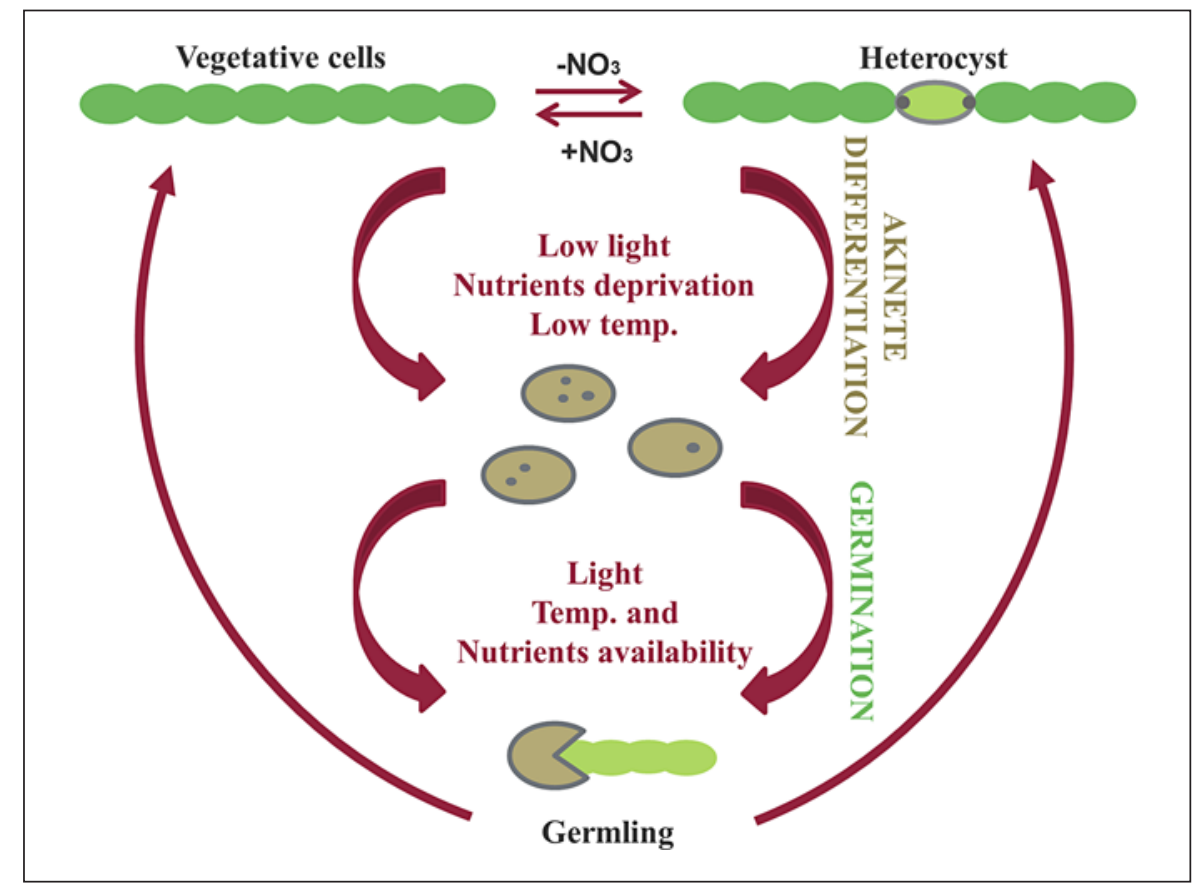

ing or gliding [Meeks et al., 2002]. Finally, many species form spore-like resting cells, called akinetes, when the environment temporarily changes to unfavorable conditions like cold winters in temperate zones [Kaplan-Levy et al., 2010]. Akinetes are transient cells which differentiate from vegetative cells to enable these bacteria to withstand harsh environmental conditions [Maldener et al., 2014; Sukenik et al., 2018]. Several environmental factors have been reported to trigger the differentiation of akinetes in a species-specific way, including light intensity, light quality, temperature, and nutrient deficiency (Fig. 1) [Sukenik et al., 2013; Maldener et al., 2014].

\section{The Akinete Structure}

Akinetes differ from vegetative cells by their cellular composition and ultra-structure and are usually larger (sometimes up to 10-fold) than vegetative cells [Adams and Duggan, 1999]. During akinete differentiation, the cells transiently accumulate storage compounds, such as carbon in the form of glycogen, nitrogen in the form of cyanophycin globules (co-polymers of arginine and aspartate), and nucleic acids [Sutherland et al., 1985; Simon, 1987; Sarma et al., 2004; Kaplan-Levy et al., 2010; Sukenik et al., 2012]. In contrast, mature akinetes drastically reduce their metabolic activities [Perez et al., 2016].

Akinetes are surrounded by a thickened cell wall and a multilayered extracellular envelope. The distinct layers of the envelope include the outermost polysaccharide lay- er, similar to the homogeneous polysaccharide layer of the heterocyst envelope, the mucilaginous layer, and the glycolipids layer, which is identical in composition to that of the heterocyst envelope and absent in vegetative cells [Cardemil and Wolk, 1981; Nichols and Adams, 1982; Soriente et al., 1993; Wolk et al., 1994; Perez et al., 2018].

Interestingly, the reserve storage materials accumulated during akinete differentiation are degraded again upon akinete maturation [Perez et al., 2016]. This suggests that large amounts of reserve material are gradually consumed for the formation of the thick and complex akinete envelope during maturation and the extended period of dormancy.

Akinete formation is a transient differentiation process; when the environmental conditions are appropriate for growth, the akinetes can germinate, releasing small filaments from the envelope that resume the vegetative cell cycle [Kaplan-Levy et al., 2010]. The presence of light, moderate temperature, and nutrient conditions favorable for growth are the major stimuli for akinete germination (Fig. 1) [Yamamoto, 1976; Rai and Pandey, 1981; Huber, 1985; Fay, 1988; Adams and Duggan, 1999; Kaplan-Levy et al., 2010]. The presence of light is required for akinete germination in Anabaena circinalis [Van Dok and Hart, 1997], A. variabilis [Perez et al., 2018], and Aphanizomenon flos-aquae [Karlsson-Elfgren and Brunberg, 2004; Karlsson-Elfgren et al., 2004]. In addition, the germination of akinetes was shown to be dependent on light intensity and did not occur in the dark or in the presence of 
the photosynthesis inhibitor 3-(3,4-dichlorophenyl)-1,1dimethylurea (DCMU) [Yamamoto, 1976; Braune, 1979].

During germination in response to medium light, cell division starts inside the envelope of $A$. variabilis akinetes, with the energy for cell division initially supplied by the respiration of glycogen and subsequently by photosynthesis [Perez et al., 2018]. In Anabaena cylindrica, oxygen and light are required for germination, indicating that respiration of reserve material and photosynthesis provide the energy and carbon for this process [Yamamoto, 1976]. The germination of akinetes in A. circinalis requires light, as mentioned previously, but also phosphate [Van Dok and Hart, 1997]. Hence, the energy for akinete germination comes from the photosynthetic activity in this species, and respiration determines the rate of germination in a temperature-dependent manner [Kezhi et al., 1985; Fay, 1988].

\section{Genes Required for Akinete Differentiation}

Many putative transcriptional regulators of heterocyst differentiation are also involved in akinete differentiation. The overexpression of the heterocyst regulatory gene $\operatorname{dev} R$, encoding a response regulator of a two-component system involved in polysaccharide biosynthesis [Zhou and Wolk, 2003], results in enhanced akinete differentiation in N. punctiforme [Campbell et al., 1996]. The transcriptional regulatory gene het $R$ was shown to be downregulated in akinetes of $N$. punctiforme, and a het $R$ mutant strain formed cold-resistant akinete-like cells [Wong and Meeks, 2002]. However, hetR was shown to be essential for both heterocyst and akinete formation in Nostoc ellipsosporum [Leganés et al., 1994]. In addition, the hepA gene product is required for the formation of the polysaccharide layer in heterocysts [Wolk et al., 1994] as well as normal envelopes in akinetes of $A$. variabilis [Leganés, 1994]. A sigma/anti-sigma factor pair Npun F4153 SigG/Npun_F4154 SapG was shown to be involved in the stress resistance mechanisms of akinetes. The transcription of sigG increases in heterocysts and akinetes, and its regulon includes genes that are mainly involved in cell envelope formation [Bell et al., 2017]. Recently, the A. variabilis $h g l B$ gene, involved in glycolipid synthesis of the heterocyst envelope, was shown to be also required for envelope formation in akinetes [Garg and Maldener, 2021]. So far, only one gene, avaK, has been identified as akinete marker gene in A. variabilis [Zhou and Wolk, 2002], but its cellular function is unknown yet. However, its homologous gene product $\mathrm{AcaK} 43$ has recently been found to be abundant in heterocysts of $A$. cylindrica [Qiu et al., 2020]. The presence of common genetic compo- nents suggests that akinetes and heterocysts share similar developmental processes but offers no clear evidence of a common regulatory pathway controlling their differentiation [Wolk et al., 1994].

\section{Role of Akinetes in Stress Resistance and Survival}

Akinetes have an ecological advantage as they can survive long enough for the environmental conditions to become favorable again for growth and to produce vegetative cyanobacteria cells. Akinetes are resistant to cold and desiccation, thereby allowing perennation or longer periods of survival [Hori et al., 2003; Kaplan-Levy et al., 2010]. They play a key role in the survival under stress conditions [Sukenik et al., 2012].

While initially reported to be sensitive to heat [Adams and Duggan, 1999], akinetes of Nostoc sp. HK-01 were recently shown to be heat tolerant as a result of the accumulation of betaine, glucosylglycerol, and glycine [Kimura et al., 2017]. Akinetes are highly resistant to dry conditions and a wide range of temperatures [Yamamoto, 1976; Kaplan-Levy et al., 2010; Kimura et al., 2015]. They have been reported to survive 5-7 years of desiccation and retain the capacity to germinate after storage in the darkness for 5 years at $27^{\circ} \mathrm{C}$ [Yamamoto, 1975; Sili et al., 1994] or months of cold $\left(4^{\circ} \mathrm{C}\right)$ dark conditions [Sutherland et al., 1979] and have been isolated from sediments as old as 64 years [Livingstone and Jaworski, 1980].

In A. cylindrica, akinetes showed high tolerance to severe drying processes and were able to germinate after heat-drying in an oven at $60^{\circ} \mathrm{C}$ for $50 \mathrm{~h}$ and drying under sunlight for $10 \mathrm{~h}$, suggesting that they are highly resistant [Hori et al., 2003]. In some cyanobacteria species, immature pre-akinetes are more tolerant to abiotic stress factors, such as osmotic stress [Kaplan et al., 2013; Pichrtová et al., 2014a], freezing [Trumhová et al., 2019], and desiccation [Pichrtová et al., 2014b]. Recently, we have also reported that the akinete envelope glycolipids are necessary to protect the akinetes from various stress conditions, such as freezing, desiccation, oxidative stress, and lysozyme attack, in A. variabilis [Garg and Maldener, 2021].

\section{The Mature Akinete and Its Germination in A. variabilis}

As akinetes are an important aspect of the cyanobacterial life cycle, more investigations are needed to understand their biology, differentiation process, and germination. Therefore, akinetes of $A$. variabilis were induced by exposure to low light as described previously [Perez et al., 2016]. We observed that during the differentiation of aki- 


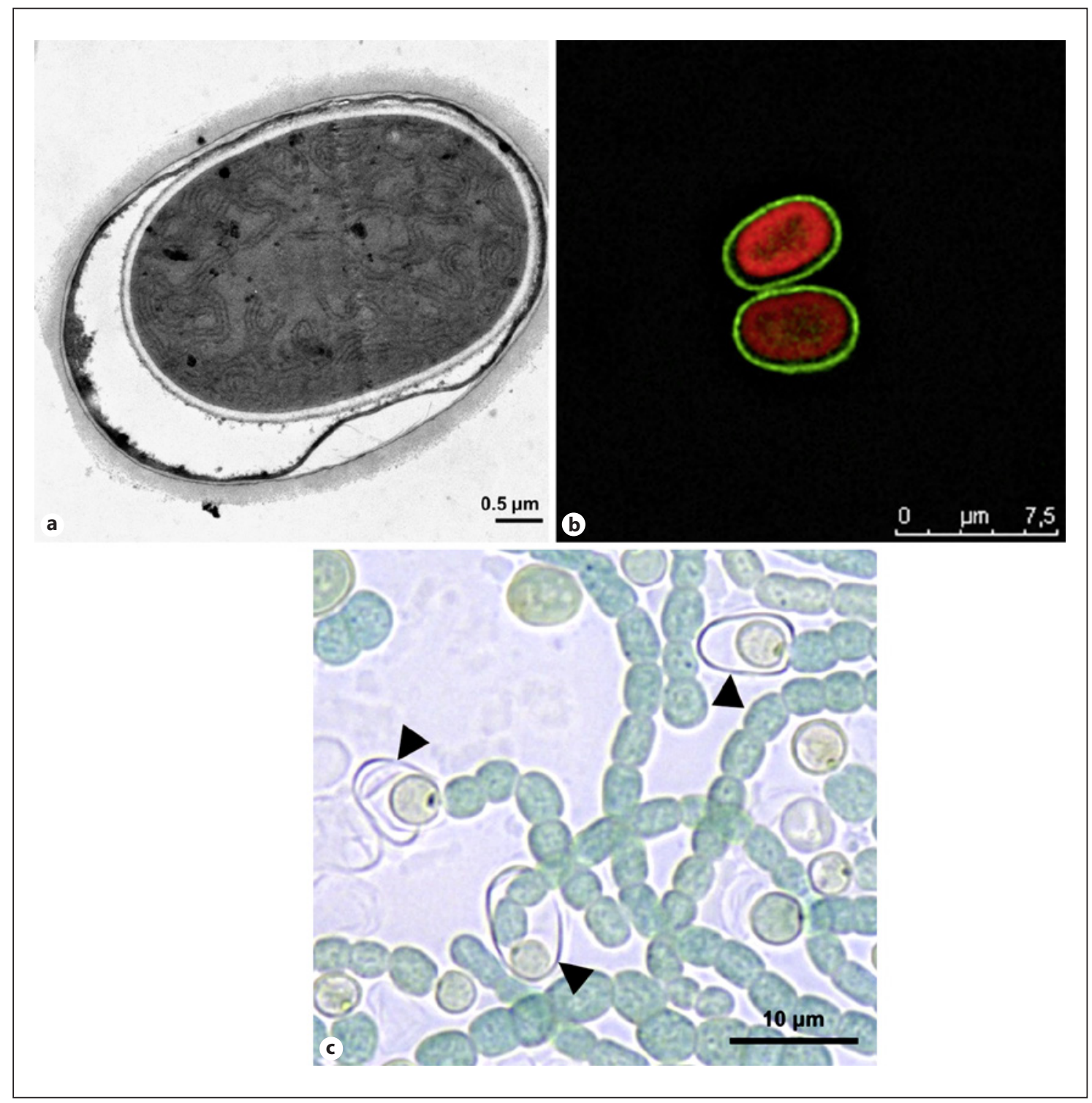

Fig. 2. Structural analysis of the akinete envelope and germination in A. variabilis. a Transmission electron micrographs of mature akinete exposed to low light for 30 days. A multilayered envelope surrounding the cell is visible. $\mathbf{b}$ In vivo visualization of the lipid layer of akinetes with the green fluorescent dye BODIPY. Shown are the overlaid images of BODIPY green fluorescence and red autofluorescence. c Bright-field micrograph showing germinating akinetes in medium lacking a source of nitrogen. Clearly, heterocyst differentiation gets induced at a very early stage of germination. Black arrowheads indicate the remaining akinete envelope after rupture.

netes from vegetative cells, many structural changes occurred, such as an increase in cell size and transient accumulation of intracellular granules like cyanophycin and glycogen [Simon, 1987; Perez et al., 2016]. Furthermore, a multilayered extracellular envelope built up, mainly consisting of an outermost polysaccharide layer and an inner glycolipid layer, as depicted in Figure 2a [see also Perez et al., 2016, 2018]. The glycolipid layer of aki- netes could also be visualized with the fluorescent green dye BODIPY, which stains the lipid layer in living cells as previously described (Fig. 2b) [Perez et al., 2018].

Further, we analyzed the changes that take place during the akinete germination process. Two-month-old akinetes of $A$. variabilis were transferred to optimum light and fresh medium to induce germination. Akinete germination started with the increase in cell size, and the first cell division 


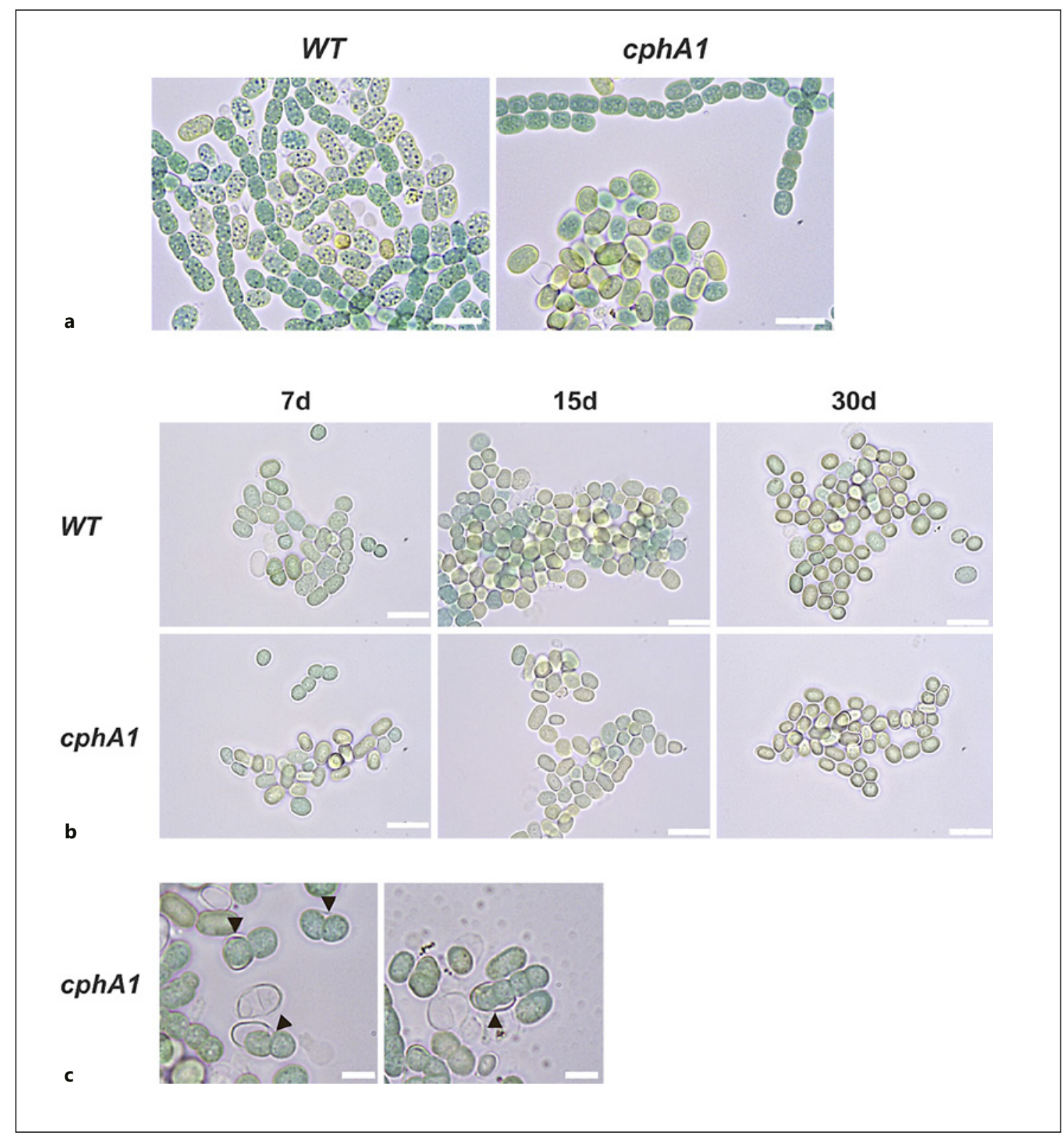

Fig. 3. Akinete differentiation and germination in the $A$. variabilis WT and $c p h A 1$ mutant. a Bright-field images of WT and mutant $c p h A 1$ akinete cultures induced by 7 days of phosphate starvation. Bars, $10 \mu \mathrm{m}$. b Akinete differentiation process in WT and mutant $c p h A 1$ strains was induced by exposure to low-light condition and monitored by light microscopy after 7 days, 15 days, and 30 days. Bars, $10 \mu \mathrm{m}$. c Bright-field micrograph showing akinete germination in cphA1 mutant. Germination of mature akinetes was induced by transferring the cultures to fresh medium and normal light conditions. Black arrowheads indicate the germinating akinetes. Bars, $5 \mu \mathrm{m}$. WT, wild type.

inside the akinete envelope was observed within 18-24 h. Successive cell divisions increased the pressure inside the envelope, which eventually ruptured and released the short filament. When using fresh nitrogen-free medium, the terminal cell began to differentiate into a heterocyst soon after the first cell division (Fig. 2c). This result clearly indicated that the germinating small filament can sense the presence/ absence of a nitrogen source at the very beginning of cell division. The heterocyst presumably performs nitrogen fixation to support the growing filament with amino acids, since the nitrogen storage compounds were used up during maturation of the dormant cell [see also Perez et al., 2018]. 


\section{Role of Cyanophycin in Akinete Differentiation and} Germination

As mentioned earlier, several cyanobacterial species are known to accumulate intracellular reserve material, such as glycogen and cyanophycin, during akinete differentiation. In Anabaena torulosa, akinetes accumulate cyanophycin during their development and decrease the amount of it when mature [Sarma and Khattar, 1986]. Similarly, Aphanizomenon ovalisporum also accumulates cyanophycin during the formation of akinetes induced by potassium starvation [Sukenik et al., 2015]. A previous study by Leganés et al. [1998] showed that cyanophycin granule formation is necessary for the function of heterocysts and akinetes in N. ellipsosporum. However, vegetative cells also accumulate glycogen and cyanophycin in the stationary growth phase and under stress conditions [Lawry and Simon, 1982; Herdman, 1987], indicating that the accumulation of reserve material is not restricted to akinete formation. Moreover, unicellular cyanobacteria, with no capacity for differentiation, accumulate storage compounds in response to starvation conditions [Doello et al., 2018; Watzer and Forchhammer, 2018]. Hence, the accumulation of reserve material is considered a general response to starvation to regulate nutrient homeostasis [Forchhammer and Schwarz, 2019].

Cyanophycin is a dynamic carbon/nitrogen storage polymer widespread among cyanobacteria and a few heterotrophic bacteria. The accumulation of cyanophycin granules in akinetes was observed for many Nostocales species [Sarma and Khattar, 1986; Sarma et al., 2004]. During germination, the degradation of cyanophycin was observed in Cylindrospermum sp. [Miller and Lang, 1968], A. flosaquae [Wildman et al., 1975], and A. cylindrica [Fay, 1969]. Mutation of the arginine biosynthesis gene, $\operatorname{argL}$, in N. ellipsosporum [Leganés et al., 1998] and incubation of $A$. cylindrica with the arginine analog, canavanine [Nichols and Adams, 1982], resulted in the production of cyanophycinlacking akinetes that were unable to germinate. This suggested the requirement of cyanophycin accumulation for the germination of akinetes, but not for its formation.

\section{Results}

\section{Characterization of a cphA Mutant}

To determine whether the cyanophycin granules that accumulate during akinete differentiation in A. variabilis are required for akinete formation and germination, we created an A. variabilis mutant void of cyanophycin synthesis. For this, the gene $c p h A 1$ encoding the cyanophycin synthetase was interrupted by insertion of a neomycin resistance cassette by double homologous recombination (see Materials and Methods). CphA catalyzes the biosynthesis of the nitrogen reserve cyanophycin (multi-L-arginyl-poly-L-aspartic acid) [Berg et al., 2000]. Under standard growth conditions in media supplemented with $\mathrm{NO}_{3}{ }^{-}$, no visible differences in cell morphology and filament length were observed in $c p h A 1$ mutant compared to the wild type (WT) (not shown). Moreover, the mutant grew similar to the WT strain on medium containing or lacking the combined nitrogen source (online suppl. Fig. S1A; see www.karger.com/doi/10.1159/000517443 for all online suppl. material). We also observed that the mutant heterocysts lacked cyanophycin polar nodules, consistent with a previous study by Ziegler et al. [2001] (online suppl. Fig. S1B).

In the cphA1 mutant, cyanophycin granules were also absent in akinetes after 7 days of phosphate starvation (Fig. 3a). In contrast to akinete induction by low light (see below), this nutrient limitation results in better synchronization. The WT akinetes clearly displayed cyanophycin granules under the same conditions. Despite the absence of cyanophycin granules, the cphA1 mutant was able to differentiate akinetes similar to the WT.

The rate of akinete formation was also investigated in a low-light condition, which is reported as a better inducing factor for akinete differentiation in $A$. variabilis [Perez et al., 2016]. The akinete development process and the rate of differentiation were similar to the WT (Fig. 3b). Also, the envelope ultra-structure was like the WT in transmission electron micrographs (data not shown). These results clearly indicate that cyanophycin is not required for akinete differentiation in A. variabilis.

Furthermore, we investigated the germination of akinetes of the cphA1 mutant to determine the role of cyanophycin granules in germination and to check the viability of the mutant akinetes. Germination of mutant $\operatorname{cph} A 1$ akinetes was induced as described above for the WT. We observed a similar germination rate and pattern for the mutant akinetes as for the WT (Fig. 3c). Altogether, these results indicate that the differentiation of akinetes in A. variabilis does not require cyanophycin and the akinetes lacking cyanophycin granules can germinate under the applied conditions.

\section{Materials and Methods}

Strains and Growth Conditions

A. variabilis ATCC 29413 strain FD [Currier and Wolk, 1979; Thiel et al., 2014] and derived mutant strains were cultivated pho- 
toautotrophically under continuous illumination (17-22 $\mu \mathrm{mol}$ photons $\mathrm{m}^{-2} \mathrm{~s}^{-1}$ ) in $100 \mathrm{~mL}$ Erlenmeyer flasks at $28^{\circ} \mathrm{C}$ with shaking at $120 \mathrm{rpm}$ in standard medium of Allen and Arnon [1955] diluted 4 -fold with water $(\mathrm{AA} / 4)$ and supplemented with $5 \mathrm{mM} \mathrm{KNO}_{3}$. The solid media remained undiluted with $1.5 \%$ (w/v) Difco Agar. The mutant strain was grown in the medium supplemented with $50 \mu \mathrm{g}$ $\mathrm{mL}^{-1}$ neomycin.

To induce heterocyst differentiation, exponentially growing cultures were washed 3 times in nitrate-free AA/4 medium, resuspended in the same medium equal to the original volume, and cultivated under nitrogen-depleted growth conditions. Chlorophyll $a$ (Chla) content of culture was determined as reported previously [Mackinney, 1941].

Escherichia coli strains were grown in lysogeny broth medium at $37^{\circ} \mathrm{C}$, supplemented with the following antibiotics: $50 \mu \mathrm{g} \mathrm{mL} \mathrm{m}^{-1}$ kanamycin $(\mathrm{Km}), 25 \mu \mathrm{g} \mathrm{mL}{ }^{-1}$ chloramphenicol $(\mathrm{Cm}), 25 \mu \mathrm{g} \mathrm{mL} \mathrm{m}^{-1}$ streptomycin $(\mathrm{Sm})$, when required. For growth on solid medium, $1.5 \%(\mathrm{w} / \mathrm{v})$ agar was added. The E. coli strain Top10 was used as a host in plasmid constructions. For triparental mating, the E. coli strain J53 (bearing the conjugative plasmid RP4), strain HB101 (bearing the helper plasmid pRL528 and the cargo plasmid), and the WT A. variabilis strain were used [Maldener et al., 1991] (online suppl. Table S1).

\section{Mutant Construction}

To construct the cphA1 mutant in A. variabilis, the gene Ava_1814 (cphA1) was interrupted by insertion of the neomycin resistance-conferring cassette (C.K3t4) into the genome by double-crossover homologous recombination. For this, the left- and right-flanking regions of $c$ phA1 were amplified by PCR using primers 2015/2016 and 2019/2020 (see online suppl. Table S2 for primers) using genomic DNA as a template and high-fidelity Q5polymerase (NEB, Ipswich, MA, USA). The C.K3t4 cassette was constructed by the modification of the previously described cassette C.K3 [Elhai and Wolk, 1988]. Briefly, the C.K3 cassette was fused to the C-terminus of the bacteriophage T4 gene 32 [Krisch and Allet, 1982] bearing a transcriptional terminator and a translation tandem stop codon. The C.K3t4 cassette was amplified using primers 2017 and 2018. All PCR products were fused into the XhoI digested suicide vector pRL277 (online suppl. Table S1) using Gibson assembly [Gibson et al., 2009]. The resulting plasmid pIM764 was transferred into $A$. variabilis WT cells using triparental mating followed by the selection of clones on neomycin and 5\% sucrosecontaining agar plates [Maldener et al., 1991]. The segregation of the mutant colony was analyzed by colony PCR and the strain was named cphA1 mutant.

\section{Akinete Differentiation and Germination}

Akinete differentiation was induced in late exponentially grown cultures by either low light or phosphate starvation. Lowlight conditions $\left(2-3 \mu \mathrm{mol}\right.$ photons $\left.\mathrm{m}^{-2} \mathrm{~s}^{-1}\right)$ were maintained by covering flasks with paper towels. For phosphate starvation, filaments were washed 3 times with AA/4 medium without inorganic phosphate and then transferred to AA/4 medium supplemented with $5 \mathrm{mM}$ MOPS buffer (pH 7.5), $2.5 \mathrm{mM} \mathrm{NH}_{4} \mathrm{Cl}, 2.5 \mathrm{mM} \mathrm{NaNO}_{3}$, and $2.5 \mathrm{mM} \mathrm{KNO}_{3}$, but lacking inorganic phosphate as described previously [Perez et al., 2016]. All induced cultures were maintained at $28^{\circ} \mathrm{C}$ with shaking at $50 \mathrm{rpm}$.

The germination of mature akinetes was induced by washing and transferring the akinete culture to either BG11 medium con- taining $\mathrm{NaNO}_{3}$ or $\mathrm{BG} 11_{0}$ medium lacking combined nitrogen and optimal light conditions [Perez et al., 2018].

The akinetes differentiation and germination process was observed by Leica DM 2500 light microscope with a $\times 100 / 1.3$ oil objective, connected to a Leica DFC420C camera (Leica Microsystems GmbH, Wetzlar, Germany).

\section{Transmission Electron Microscopy}

For electron microscopy, the akinete cells were fixed with $2.5 \%$ glutaraldehyde followed by postfixation with $2 \%$ potassium permanganate and immobilization in agarose. Upon dehydration by successive increment of the ethanol concentration, the samples were embedded in Epon. Ultrathin sections were stained with uranyl acetate and lead citrate [Fiedler et al., 1998] and examined with a Philips Tecnai 10 electron microscope at $80 \mathrm{kHz}$.

\section{BODIPY Staining}

To visualize the glycolipid layer in akinetes envelope, samples of akinete culture were stained with boron-dipyrromethene difluoride (BODIPY) 493/503 (Molecular Probes, Thermo Fisher Scientific, Waltham, MA, USA) as described previously [Perez et al., 2016]. After staining, filaments were placed on the slides covered with $1.5 \%$ agarose and observed by light microscopy with a Leica DM 2500 microscope connected to a Leica DFC420C camera or with a Leica DM 5500B fluorescence microscope connected to a Leica DFC420C camera. The green fluorescence signal was monitored with a BP470 40-nm excitation filter and a BP525 50-nm emission filter.

\section{Conclusions}

The aim of our studies was to understand the changes in morphology and physiology in more detail during the formation and germination of akinetes in the model organism A. variabilis ATCC 29413 and discern the longterm survival strategy of these spore-like cells. Various environmental signals were reported to trigger akinete differentiation and germination. However, these processes are still not well understood at the cellular and molecular level [Adams and Duggan, 1999; Kaplan-Levy et al., 2010; Maldener et al., 2014].

A. variabilis akinetes have a multi-layered envelope required for surviving harsh environmental conditions. We have shown recently that this reliable barrier between the dormant akinete cell and the harsh conditions is determined by the chemical composition and fine structure of the akinete envelope, especially the presence of a glycolipid layer [Perez et al., 2018; Garg and Maldener, 2021].

Like akinete differentiation, the germination of mature akinetes of $A$. variabilis is a highly asynchronous process. Various environmental stimuli, such as moderate temperature, increased light intensity, sediment resus- 
pension, and nutrition, can trigger akinete germination [Huber, 1985; Van Dok and Hart, 1997; Karlsson-Elfgren and Brunberg, 2004; Perez et al., 2016].

The presence of a nitrogen source was not needed for germination and reflects the diazotrophic lifestyle of these cyanobacteria, which form heterocysts in the freshly germinated filaments.

We clarified the biological function of cyanophycin in akinetes differentiation and germination in A. variabilis and showed that cyanophycin provides the WT cyanobacterium with no advantage over the non-cyanophycinproducing mutant (online suppl. Fig. S1) consistent with the previous report [Ziegler et al., 2001]. It remains unknown for which processes cyanophycin is being utilized in akinetes. It might be possible that cyanophycin provides some structural stability to the akinetes during long harsh unfavorable conditions, which needs to be further elucidated.

The availability of the data from fully sequenced genomes of several Nostocales species and implementation of various molecular and genomic tools ensure the advancement of a better understanding of the dormancy phenomenon in cyanobacteria. Additionally, to promote the understanding of akinete differentiation, survival, and germination, further elaboration of methods for mutational analysis and cellular characterization of mutants specifically impaired in the cellular function of akinete is needed.

\section{Acknowledgments}

We thank Claudia Menzel for technical assistance and Prof. Karl Forchhammer for helpful discussions. We would like to thank Libera Lo Presti for critical reading and editing of the manuscript.

\section{Statement of Ethics}

No ethical approval was sought as neither human or animal participation was involved.

\section{Conflict of Interest Statement}

The authors have no conflicts of interest to declare.

\section{Funding Sources}

This work was funded by the grant GRK1708 from the Deutsche Forschungsgemeinschaft (DFG, German Research Foundation).

\section{Author Contributions}

R.G. designed and performed the experiments, interpreted the data, and wrote most parts of the manuscript. I.M. designed and supervised the experiments, wrote part of the manuscript, revised the work critically for important intellectual content, and gave the final approval. All authors made substantial contributions to the design of the work and performed acquisition, analysis, and interpretation of data for the work. All authors agreed to be accountable for all aspects of the work in ensuring that questions related to the accuracy or integrity of any part of the work were appropriately investigated and resolved.

\section{References}

Adams DG, Duggan PS. Tansley Review No. 107. Heterocyst and akinete differentiation in cyanobacteria. New Phytologist. 1999;144(1):3-33.

Allen MB, Arnon DI. Studies on nitrogen-fixing blue-green algae. I. Growth and nitrogen fixation by Anabaena cylindrica Lemm. Plant Physiol. 1955;30(4):366-72.

Bell N, Lee JJ, Summers ML. Characterization and in vivo regulon determination of an ECF sigma factor and its cognate anti-sigma factor in Nostoc punctiforme. Mol Microbiol. 2017; 104(1):179-94

Berg H, Ziegler K, Piotukh K, Baier K, Lockau W, Volkmer-Engert R. Biosynthesis of the cyanobacterial reserve polymer multi-L-arginylpoly-L-aspartic acid (cyanophycin): Mechanism of the cyanophycin synthetase reaction studied with synthetic primers. Eur J Biochem. 2000;267(17):5561-70.

Braune W. C-Phycocyanin - the main photoreceptor in the light dependent germination process of Anabaena akinetes. Arch Microbiol. 1979;122(3):289-95.
Campbell EL, Hagen KD, Cohen MF, Summers ML, Meeks JC. The devR gene product is characteristic of receivers of two-component regulatory systems and is essential for heterocyst development in the filamentous cyanobacterium Nostoc sp. strain ATCC 29133. J Bacteriol. 1996;178(7):2037-43.

Cardemil L, Wolk CP. Polysaccharides from the envelopes of heterocysts and spores of the blue-green algae Anabaena variabilis and Cylindrospermum licheniforme 1. J Phycol. 1981;17(3):234-40.

Currier TC, Wolk CP. Characteristics of Anabaena variabilis influencing plaque formation by $\mathrm{cy}$ anophage N-1. J Bacteriol. 1979;139(1):88-92.

Doello S, Klotz A, Makowka A, Gutekunst K, Forchhammer K. A specific glycogen mobilization strategy enables rapid awakening of dormant cyanobacteria from chlorosis. Plant Physiol. 2018;177(2):594-603.

Van Dok W, Hart BT. Akinete germination in Anabaena circinalis (Cyanophyta). J Phycol. 1997;33(1):12-7.
Elhai J, Wolk CP. Conjugal transfer of DNA to cyanobacteria. Methods Enzymol. 1988; 167(C):747-54.

Fay P. Metabolic activities of isolated spores of Anabaena cylindrica. J Exp Bot. 1969;20(1): 100-9.

Fay P. Viability of akinetes of the planktonic cyanobacterium Anabaena circinalis. Proc R Soc Lond B. 1988;234(1276):283-301.

Fiedler G, Arnold M, Hannus S, Maldener I. The DevBCA exporter is essential for envelope formation in heterocysts of the cyanobacterium Anabaena sp. strain PCC 7120. Mol Microbiol. 1998;27(6):1193-202.

Flores E, Herrero A, Forchhammer K, Maldener I. Septal junctions in filamentous heterocystforming cyanobacteria. Trends Microbiol. 2016;24(2):79-82.

Flores E, Nieves-Morión M, Mullineaux CW. Cyanobacterial septal junctions: Properties and regulation. Life (Basel). 2019;9(1):1-14. 
Forchhammer K, Schwarz R. Nitrogen chlorosis in unicellular cyanobacteria - a developmental program for surviving nitrogen deprivation. Environ Microbiol. 2019;21(4):1173-84.

Garg R, Maldener I. The dual role of the glycolipid envelope in different cell types of the multicellular cyanobacterium Anabaena variabilis ATCC 29413. Front Microbiol. 2021;12:645028.

Gibson DG, Young L, Chuang RY, Venter JC, Hutchison CA, Smith HO. Enzymatic assembly of DNA molecules up to several hundred kilobases. Nat Methods. 2009;6(5):343-5.

Herdman M. Akinetes: structure and function. In: Fay P, Van Baalen C, editors. The Cyanobacteria. Amsterdam: Elsevier; 1987. p. 227-50.

Hori K, Okamoto Ji., Tanji Y, Unno H. Formation, sedimentation and germination properties of Anabaena akinetes. Biochem Eng J. 2003;14(1):67-73.

Huber AL. Factors affecting the germination of akinetes of Nodularia spumigena (Cyanobacteriaceae). Appl Environ Microbiol. 1985; 49(1):73-8.

Kaplan-Levy RN, Hadas O, Summers ML, Rücker J, Sukenik A. Akinetes: Dormant cells of cyanobacteria. Top Curr Genet. 2010;21:5-27.

Kaplan F, Lewis LA, Herburger K, Holzinger A. Osmotic stress in Arctic and Antarctic strains of the green alga Zygnema (Zygnematales, Streptophyta): Effects on photosynthesis and ultrastructure. Micron. 2013;44(1):317-30.

Karlsson-Elfgren I, Brunberg AK. The importance of shallow sediments in the recruitment of Anabaena and Aphanizomenon (Cyanophyceae). J Phycol. 2004;40(5):831-6.

Karlsson-Elfgren I, Rengefors K, Gustafsson S. Factors regulating recruitment from the sediment to the water column in the bloom-forming cyanobacterium Gloeotrichia echinulata. Freshwater Biol. 2004;49(3):265-73.

Kezhi B, Guoliang W, Cheng C. Studies on the mechanism of light-dependent germination of akinetes of blue-green algae. Hydrobiologia. 1985;123(1):89-91.

Kieninger AK, Forchhammer K, Maldener I. A nanopore array in the septal peptidoglycan hosts gated septal junctions for cell-cell communication in multicellular cyanobacteria. Int J Med Microbiol. 2019;309(8):151303.

Kimura S, Ong M, Ichikawa S, Tomita-Yokotani $\mathrm{K}$. Compatible solutes in the akinetes of the terrestrial cyanobacterium Nostoc sp. HK-01 contribute to its heat tolerance. Am J Plant Sci. 2017;08(11):2695-711.

Kimura S, Tomita-Yokotani K, Igarashi Y, Sato S, Katoh H, Abe T, et al. The heat tolerance of dry colonies of a terrestrial cyanobacterium, Nostoc sp. HK-01. Biol Sci Space. 2015;29(0): 12-8.

Krisch HM, Allet B. Nucleotide sequences involved in bacteriophage T4 gene 32 translational self-regulation. Proc Natl Acad Sci U S A. 1982;79(16):4937-41.

Lawry NH, Simon RD. The normal and induced occurrence of cyanophycin inclusion bodies in several blue-green algae. J Phycol. 1982; 18(3):391-9.
Leganés F. Genetic evidence that hepA gene is involved in the normal deposition of the envelope of both heterocysts and akinetes in Anabaena variabilis ATCC 29413. FEMS Microbiol Lett. 1994;123(1-2):63-7.

Leganés F, Fernández-Piñas F, Wolk CP. A transposition-induced mutant of Nostoc ellipsosporum implicates an arginine-biosynthetic gene in the formation of cyanophycin granules and of functional heterocysts and akinetes. Microbiology. 1998;144(7):1799805.

Leganés F, Fernández-Piñas F, Wolk CP. Two mutations that block heterocyst differentiation have different effects on akinete differentiation in Nostoc ellipsosporum. Mol Microbiol. 1994;12(4):679-84.

Livingstone D, Jaworski GHM. The viability of akinetes of blue-green algae recovered from the sediments of rostherne mere. Br Phycol J. 1980;15(4):357-64.

Mackinney G. Absorption of light by chlorophyll solutions. J Biol Chem. 1941;140(2):315-22.

Maldener I, Lockau W, Cai YP, Wolk CP. Calcium-dependent protease of the cyanobacterium Anabaena: molecular cloning and expression of the gene in Escherichia coli, sequencing and site-directed mutagenesis. Mol Gen Genet. 1991;225(1):113-20.

Maldener I, Summers ML, Sukenik A. Cellular differentiation in filamentous cyanobacteria. In: Flores E, Herrero A, editors. The Cell Biology of Cyanobacteria. UK: Caister Academic Press; 2014. p. 263-91.

Meeks JC, Campbell EL, Summers ML, Wong FC. Cellular differentiation in the cyanobacterium Nostoc punctiforme. Arch Microbiol. 2002;178(6):395-403.

Miller MM, Lang NJ. The fine structure of akinete formation and germination in Cylindrospermum. Arch Mikrobiol. 1968;60(4):303-13.

Nichols JM, Adams DG. Akinetes. In: Carr NG, Whitton BA, editors. The biology of cyanobacteria. Oxford, UK: Blackwell; 1982. p. 387412.

Perez R, Forchhammer K, Salerno G, Maldener I. Clear differences in metabolic and morphological adaptations of akinetes of two Nostocales living in different habitats. Microbiology (Reading). 2016;162(2):214-23.

Perez R, Wörmer L, Sass P, Maldener I. A highly asynchronous developmental program triggered during germination of dormant akinetes of filamentous diazotrophic cyanobacteria. FEMS Microbiol Ecol. 2018;94(1): 1-11.

Pichrtová M, Hájek T, Elster J. Osmotic stress and recovery in field populations of Zygnema sp. (Zygnematophyceae, Streptophyta) on Svalbard (high arctic) subjected to natural desiccation. FEMS Microbiol Ecol. 2014a;89(2): $270-80$.

Pichrtová M, Kulichová J, Holzinger A. Nitrogen limitation and slow drying induce desiccation tolerance in conjugating green algae (Zygnematophyceae, Streptophyta) from polar habitats. PLoS One. 2014b;9(11).
Qiu Y, Gu L, Brözel V, Whitten D, Hildreth M, Zhou R. Unique proteomes implicate functional specialization across heterocysts, akinetes, and vegetative cells in Anabaena cylindrica. bioRxiv. 2020.

Rai AK, Pandey GP. Influence of environmental stress on the germination of Anabaena vaginicola akinetes. Ann Bot. 1981;48(3):361-70.

Sarma TA, Ahuja G, Khattar JI. Nutrient stress causes akinete differentiation in cyanobacterium Anabaena torulosa with concomitant increase in nitrogen reserve substances. Folia Microbiol (Praha). 2004;49(5):557-61.

Sarma TA, Khattar JIS. Accumulation of cyanophycin and glycogen during sporulation in the blue-green alga Anabaena torulosa. Biochem Physiol Pflanz. 1986;181(3):155-64.

Sili C, Ena A, Materassi R, Vincenzini M. Germination of desiccated aged akinetes of alkaliphilic cyanobacteria. Arch Microbiol. 1994; 162(1-2):20-5.

Simon RD. Inclusion bodies in the cyanobacteria: cyanophycin, polyphosphate, polyhedral bodies. In: Fay P, van Baalen C, editors. The Cyanobacteria. Amsterdam; Elsevier: 1987. p. 199-225.

Soriente A, Gambacorta A, Trincone A, Sili C, Vincenzini M, Sodano G. Heterocyst glycolipids of the cyanobacterium Cyanospira rippkae. Phytochemistry. 1993;33(2):393-6.

Sukenik A, Kaplan-Levy RN, Viner-Mozzini Y, Quesada A, Hadas O. Potassium deficiency triggers the development of dormant cells (akinetes) in Aphanizomenon ovalisporum (Nostocales, Cyanoprokaryota). J Phycol. 2013;49(3):580-7.

Sukenik A, Kaplan-Levy RN, Welch JM, Post AF. Massive multiplication of genome and ribosomes in dormant cells (akinetes) of Aphanizomenon ovalisporum (Cyanobacteria). ISME J. 2012;6(3):670-9.

Sukenik A, Maldener I, Delhaye T, Viner-Mozzini Y, Sela D, Bormans M. Carbon assimilation and accumulation of cyanophycin during the development of dormant cells (akinetes) in the cyanobacterium Aphanizomenon ovalisporum. Front Microbiol. 2015;6:1067.

Sukenik A, Rücker J, Maldener I. Dormant cells (akinetes) of filamentous cyanobacteria demonstrate a great variability in morphology, physiology, and ecological function. In: Mishra AK, Tiwari DN, Rai AN, editors. Cyanobacteria: From Basic Science to Applications. Elsevier; 2018. p. 65-77.

Sutherland JM, Herdman M, Stewart WDP. Akinetes of the cyanobacterium Nostoc PCC 7524: Macromolecular composition, structure and control of differentiation. J Gen Microbiol. 1979;115(2):273-87.

Sutherland JM, Stewart WDP, Herdman M. Akinetes of the cyanobacterium Nostoc PCC 7524: morphological changes during synchronous germination. Arch Microbiol. 1985; 142(3):269-74.

Thiel T, Pratte BS, Zhong J, Goodwin L, Copeland A, Lucas S, et al. Complete genome sequence of Anabaena variabilis ATCC 29413. Stand Genomic Sci. 2014;9(3):562-73. 
Trumhová K, Holzinger A, Obwegeser S, Neuner G, Pichrtová $\mathrm{M}$. The conjugating green alga Zygnema sp. (Zygnematophyceae) from the arctic shows high frost tolerance in mature cells (pre-akinetes). Protoplasma. 2019; 256(6):1681-94.

Watzer B, Forchhammer K. Cyanophycin synthesis optimizes nitrogen utilization in the unicellular cyanobacterium Synechocystis sp. strain PCC 6803. Appl Environ Microbiol. 2018;84(20).

Weiss GL, Kieninger AK, Maldener I, Forchhammer K, Pilhofer M. Structure and function of a bacterial gap junction analog. Cell. 2019; 178(2):374-e15.
Wildman RB, Loescher JH, Carol LW. Development and germination of akinetes of Aphanizomenon flos-aquae. J Phycol. 1975;11(1): 96-104.

Wolk CP, Ernst A, Elhai J. Heterocyst metabolism and development. In: The Molecular Biology of Cyanobacteria. Springer Netherlands; 1994. p. 769-823

Wong FCY, Meeks JC. Establishment of a functional symbiosis between the cyanobacterium Nostoc punctiforme and the bryophyte Anthoceros punctatus requires genes involved in nitrogen control and initiation of heterocyst differentiation. Microbiology (Reading). 2002;148(Pt 1):315-23.

Yamamoto Y. Effect of desiccation on the germination of akinetes of Anabaena cylindrica. Plant Cell Physiol. 1975;16(4):749-52.
Yamamoto Y. Effect of some physical and chemi$\mathrm{cal}$ factors on the germination of akinetes of Anabaena cylindrica. J Gen Appl Microbiol. 1976;22(6):311-23.

Zhou R, Wolk CP. Identification of an akinete marker gene in Anabaena variabilis. J Bacteriol. 2002;184(9):2529-32.

Zhou R, Wolk CP. A two-component system mediates developmental regulation of biosynthesis of a heterocyst polysaccharide. J Biol Chem. 2003;278(22):19939-46.

Ziegler K, Stephan DP, Pistorius EK, Ruppel HG, Lockau W. A mutant of the cyanobacterium Anabaena variabilis ATCC 29413 lacking cyanophycin synthetase: Growth properties and ultrastructural aspects. FEMS Microbiol Lett. 2001;196(1):13-8. 